\section{MEI}

II, vol. 3

$n^{0} 4$

\title{
Difusión de documentación primaria digitalizada como arma de doble filo en la Historia. Un ensayo futurista
}

\author{
Leonor Zozaya Montes \\ Universidad Complutense de Madrid
}

\section{Resumen}

Actualmente es normal que las instituciones digitalicen documentos históricos, y que los pongan al servicio de los internautas de forma gratuita. Ello tiene infinidad de ventajas;

Recibido el 15-06-2011 Aceptado en 19-09-2011 por ejemplo, facilita que proliferen de estudios referidos al pasado. Esa digitalización está comúnmente financiada (o cofinanciada) por el Estado; así, en definitiva, indirectamente la sufraga la sociedad con sus impuestos. Este ensayo trata de esa documentación digitalizada, en relación con los usos politizados de la Historia y las políticas autonómicas. Reflexiona sobre futuribles, y plantea la hipótesis de qué sucedería si esas investigaciones históricas (fruto resultante de digitalización de documentos sufragadas por el Estado) se usasen con fines políticos, para alegar un rico pasado diferencial respecto al país, y así reclamar más autonomía, independencia o prebendas políticas al Estado que financió la digitalización.

\section{Palabras clave}

Historia, documentación digitalizada, Sesgo, Nacionalismo, Autonomía, Difusión de la información.

Dissemination of primary documents scanned as double-edged sword in history. A futuristic test Abstract

Nowadays it is normal for institutions to digitalize their original and historical documents and put them on the Internet for free. This digitalization is usually funded (all or in part) by the State, which society pays for indirectly with taxes. This essay focuses on these digitalized documents in relation to their political use. It reflects on future possibilities, and on what would happen if historical research (resulting from the digital documentation paid by the State) were used for political ends, to present a different past for the rest of the country with the aim to demand more autonomy, independence or political privileges to the State that paid for the digitalization.

\section{Keywords}

History, Digital documents, Bias, Nationalism, Autonomies, Diffusion of the information.

"En un Futuro remoto, la humanidad ha colonizado la Vía Láctea [...] Tiresias, un genio de las matemáticas sociales, ha encontrado la forma de calcular, mediante intrincadas ecuaciones, el devenir de la Historia. Así, le es dado a conocer que, muy pronto [...]”.

Isaac Asimov: Fundación.

Ensayistas y literatos han soñado con imaginar el futuro. En una línea similar, ensayistas e historiadores han jugado a combinar variables para adivinar cómo hubiera cambiado el presente si el pasado hubiera sido diferente, insertos en tendencias historiográficas contrafactuales. Los cambios en el paradigma científico han hecho ver que la intuición, 
aplicada a la ciencia, no es una limitación (Fernández-Mayoralas Palomeque, J., 2000: 286). Más bien al contrario, la intuición puede ayudar a plantear un sinfín de posibilidades de análisis. Por ello, también puede resultar útil para entender fenómenos del pasado, del presente e incluso para vaticinar el futuro, dado que la Historia se repite en espiral. Así lo han expresado diversas teorías procedentes de materias como Filosofía de la Historia; entre ellas, las dadas en el siglo XVII por Giambattista Vico (Fabiani, P, 2009).

La Historia científica se basa en documentación primaria y secundaria. Una de las grandes ventajas de la evolución tecnológica es que actualmente se ha generalizado la digitalización de documentos con acceso libre en Internet. Ello ha creado una globalización de información repleta de ventajas para la enseñanza y la difusión de la información y la cultura. Incluso, ha generado nuevas formas de escritura y lectura (Chartier, R., 2012).

Acaso debido a las múltiples ventajas de la digitalización de la documentación, la sociedad apenas reflexiona sobre sus posibles aspectos negativos. Sin embargo, en ciertos momentos cabría plantear hasta qué punto divulgar información o hacer investigaciones históricas puede dejar de ser un acto ingenuo y filantrópico. Recuérdese que la Historia no siempre es inocente, y que es redactada por personas, lo cual obviamente le dota de una carga trascendental de subjetividad, politizada en numerosas ocasiones. Así, la Historia es lo que quienes la cuentan quieren que sea.

Este ensayo reflexiona sobre la hipotética situación consistente en que un lugar perteneciente a un Estado, como por ejemplo una autonomía, digitalice documentación primaria gracias a la ayuda de un gobierno centralizador, con el fin de que se estudie más su pasado, y que finalmente se politice esa Historia y reivindique más autonomía o prebendas políticas. De esa forma, este ensayo advierte de una situación que podría acaecer en un futuro próximo: la utilización de información de forma oportunista, cuando se politiza con fines interesados e irrespetuosos con la Historia.

Para exponer esas ideas, este artículo trata varios puntos. Comienza hablando de las ventajas y las desventajas de la digitalización documental. Después, saca a colación la subjetividad y la ideología en la Historia, con un ejemplo ilustrativo sobre los usos politizados en el pasado. Más adelante habla de cómo los historiadores han hipotetizado sobre otros presentes y otros pasados mediante, por ejemplo, la Historia Contrafactual. Trata también sobre la experiencia de los nacionalismos independentistas, así como sobre la creación de las autonomías en España, que apelan a la Historia para legitimar ideologías vinculadas a la identidad de una nación.

\section{Ucronía, historia contrafactual y futurismo}

Este ensayo se tilda de futurista porque supone una actitud reflexiva orientada hacia el futuro. En ello difiere de la Historia Contrafactual y de la ucronía, enfocadas al pasado. La ucronía es una corriente literaria consistente en la "reconstrucción lógica, aplicada a la Historia, dando por supuestos acontecimientos no sucedidos, pero que 
habrían podido suceder" (voz ucronía, RAE, 2010). Es decir, la ucronía se centra en imaginar cómo podría haber sido el pasado si en un momento dado hubiera ocurrido algo diferente a lo que realmente ocurrió. De forma similar, pero desde un punto de vista histórico científico, la Historia Contrafactual consiste esencialmente en reflexionar sobre la pregunta ¿qué hubiera sucedido si...? más un hecho paradigmático, por ejemplo: ¿...si el general Prim no hubiese sido asesinado, o si Franco hubiese logrado que España entrase en la Segunda Guerra Mundial?. Al respecto, es fundamental la obra compilada por N. Towson (2004).

El presente artículo, lejos de bosquejar "qué hubiera pasado si”, como hacen las citadas disciplinas enfocadas al pasado, plantea ¿qué pasaría si...?, orientando la cuestión al futuro, imaginándolo. Juega con axiomas de probabilidad, especulando sobre lo que podría suceder, dentro de un proceso aleatorio relacionado con la experiencia de la Historia. Es, en definitiva, un ejercicio de Historia imaginaria o virtual, en tanto en cuanto no es real, trata sobre hechos que no han ocurrido, pero que podrían suceder.

\section{Ventajas y desventajas de los archivos digitalizados en Internet}

La comunidad científica internacional loa de forma constante las ventajas derivadas de digitalizar documentación archivística y colgarla en Internet. Personalmente, también defiendo que es fundamental para la divulgación científica. Además, opino que supone uno de los mejores recursos docentes para ofrecer conocimiento gratuitamente en cualquier parte del globo (Zozaya, L., 2009).

Por fortuna, actualmente es normal que instituciones públicas y privadas cuelguen documentos históricos en Internet. Desde documentación primaria de archivos y bibliotecas, hasta documentación secundaria, como libros o artículos, lo que permite hacer estudios sin moverse del ordenador; como por ejemplo, de Historia del Derecho, (Carabias, A., 2005). Por un lado, tienen el propósito de preservar tanto la información como el propio soporte documental. La digitalización es fundamental para conservar los documentos, pues además de que reduce el uso del original. Así, en caso de que el original se pierda debido a algún accidente, catástrofe o negligencia, la información se preservará en la copia digital, con unas características visuales de alta calidad. Además, se podrá consultar desde cualquier ordenador en cualquier parte del mundo.

Por otro lado, la digitalización documental tiene el propósito de difundir información sobre el pasado de un lugar, una institución o una persona, al facilitar que los investigadores puedan rescatar su Historia. Así, cuanta más documentación se digitalice de un lugar, más se podrá profundizar en su pasado. Todo son ventajas que promueven que el citado sistema telemático se use tanto en docencia como en investigación (Fernández Izquierdo, F., 2006). Dado que el volumen digitalizado es ingente, es posible realizar infinitas investigaciones históricas sin moverse de casa; de ese modo, el usuario ahorra tiempo y dinero, al evitar desplazamientos y otras actividades que comportan gastos extraordinarios. Ese servicio es gratuito para el usuario y permite su consulta casi desde cualquier país del mundo, prácticamente al 
instante.

Pero este servicio no es gratuito para todos. Cuesta mucho dinero a la institución que digitaliza y describe esa documentación. Igualmente, cuesta mucho a los ciudadanos que pagan con sus impuestos los gastos estatales, cuando se trata de instituciones públicas. Desde este punto de vista, el proceso de digitalización también cuenta con diversas desventajas. En efecto, previamente esos documentos han sido digitalizados, labor que habrá sido financiada por los impuestos de los ciudadanos. Esa digitalización requiere personal cualificado para copiar (fotografiando generalmente), describir y tratar adecuadamente las fuentes primarias. Según consta en numerosas webs, los proyectos de digitalización de documentación de archivos, estatales o autonómicos, normalmente han sido financiados por entidades públicas, apoyados generalmente por el Ministerio de Cultura en el caso español. Algunos archivos privados también cuentan con subvenciones estatales que patrocinan la digitalización.

Además, existen otros estudios han destacado puntos negativos, como ha señalado Anaclet Pons (2006). Entre ellos: que sólo una minoría los usa en el planeta (p. 113); que es común que las búsquedas creen desorientación en el usuario, sobre todo en lo que respecta a la calidad y la fiabilidad de la información, así como que haya desequilibrios en la cantidad de datos ofrecida (p. 114); que las facilidades del soporte digital se traduzcan en que la sociedad confunda información con conocimiento, sin la elaboración intelectual requerida (pp. 129-130). También ha advertido de que muchos lugares puedan dejar de ser gratuitos el día de mañana (p. 116).

\section{Subjetividad e ideología aplicados al pasado: usos politizados en la historia}

La Historia como disciplina científica es humana, porque la protagonizan y la escriben los hombres. Por tanto, la Historia acostumbra a tener los mismos defectos de sus autores: es tan tendenciosa como subjetiva, dado que intenta explicar hechos y procesos del pasado desde una perspectiva inmersa en un sistema ideológico, de forma consciente o inconsciente, voluntaria o involuntaria. La mención a la ideología obliga a recordar que la política oportunista siempre ha utilizado a la Historia a su antojo, intencionadamente o no, por interés, ignorancia u otras causas. La política siempre se ha usado en la Historia desde muy diversos puntos de vista (Febvre, L. 1970).

Los ejemplos que ilustran usos ideológicos y politizados de la Historia son ingentes. Uno relativamente reciente, conocido por la polémica que ha generado, ha sido el caso del Diccionario Biográfico Español de la Real Academia de la Historia, subvencionado con más de seis millones de euros del Gobierno español ${ }^{1}$. Aparte de loables contribuciones, y sin ánimo de restar méritos a nadie, la polémica estuvo servida porque varias voces eran tendenciosas. Entre ellas, destacaba la voz Francisco Franco, realizada por Luis Suárez (medievalista y presidente de la hermandad del Valle de los Caídos), quien aseveraba que Franco "montó un régimen autoritario pero no totalitario" (Constenla, T., 2011).

Sin embargo, hay documentos que desmienten esa afirmación. Principalmente cabe 
traer a colación al propio Francisco Franco cuando, en su "Discurso de la victoria” (1939), definió su régimen como totalitarista. Él mismo, al usurpar el poder, dijo textualmente: "Un Estado totalitario armonizará en España el funcionamiento de todas las capacidades y energías del país, en el que, dentro de la unidad nacional [...]” (discurso de consulta gratuita en Internet) ${ }^{2}$. La misma voz Francisco Franco, además, explica que "una guerra de casi tres años le permitió derrotar a un enemigo que en principio contaba con fuerzas superiores” (Lucas, A., 2011).

La Real Academia de la Historia, sometida a diversas presiones, parece que se ha comprometido a revisar esa versión, que algunos consideran provocativamente subjetiva. Además de las presiones públicas de la sociedad, la Asociación de Historia Contemporánea envió un comunicado a sus socios afirmado que "Algunos asociados han manifestado por escrito a la Real Academia de la Historia su desacuerdo con la elaboración de dicho texto, solicitando además que, en el caso de no mediar rectificación en la versión digital e impresa, se procediera a eliminar sus contribuciones, devolviendo la cantidad que en su día se les abonó por ello" (AHC, correo electrónico enviado el 23/06/2011).

Sorprende que, en la sociedad actual de la globalización de la información, se defina al franquismo como una cuestión de opinión, o se presente aquella guerra como si hubiese surgido por generación espontánea. Dicha voz de enciclopedia omite que Franco lideró del golpe de Estado militar que derrocó al gobierno legítimo elegido democráticamente, denominado Segunda República. Por las razones aducidas, considero que la voz Franco del Diccionario Biográfico es subjetiva y tendenciosa. En relación con la digitalización de la documentación de aquel régimen, y a modo informativo, cabe mencionar que actualmente, gracias a la Ley de la Memoria Histórica (Ley 52/2007)3, es posible consultar gran parte de los fondos de la dictadura franquista. Por ejemplo, en el Portal de víctimas de la Guerra Civil y Represaliados del franquismo ${ }^{4}$.

¿Por qué saco a colación un tema tan polémico? Porque es buen ejemplo politizado para plantear lo siguiente: si la Historia conocida se desvirtúa con temas de actualidad que la sociedad conoce, ¿qué puede suceder con temáticas históricas más antiguas y desconocidas, que pueden ser más fáciles de desvirtuar?

Aquí redirijo el discurso a otra reflexión, para plantear qué sucedería si alguien quisiese desvirtuar la Historia con fines políticos, sobre la base de la cantidad de documentación digitalizada que tuviera un lugar (por ejemplo, una autonomía), aplicando una lógica proporcional. Es decir: quien tiene equis documentación tiene equis Historia, y quien tiene equis Historia puede reclamar más prebendas. Imaginemos por ejemplo una autonomía cuelga en Internet una cantidad ingente de documentación digitalizada. Sería normal que se redactasen investigaciones de su Historia en forma de tesis doctorales o de artículos; téngase en cuenta que es muy común parcelar estudios a regiones, dado que numerosas becas de las universidades autonómicas favorecen las investigaciones del lugar en cuestión. También podría ser normal que el siguiente paso fuese alejarse del campo científico y acercarse al político, para reclamar mayor independencia o más subvenciones del Estado. 


\section{De los nacionalismos en Europa a las autonomías en España}

Los nacionalismos políticos siempre se han servido de la Historia y, por extensión, de los archivos, como medio para su fin consistente en justificar un pasado que les diferenciaba. Caso sintomático fueron los nacionalismos europeos del siglo XIX, tras la Revolución Francesa, las guerras de liberación nacional, el auge del romanticismo y del posterior desarrollo de los nacionalismos. Esos movimientos revalorizaron elementos tan significativos de una patria como su memoria, la cual se conservaba en esencia pura en los archivos, a donde había de acudir para hallar las lejanas raíces de cada nación. Así, se tendía a buscar en la Historia una legitimación política vinculada a la identidad de una nación.

Actualmente, Europa tiende a unirse mientras España parece ir a contracorriente tendiendo a la división, anacrónicamente desde un punto de vista histórico. En los años ochenta la película Las autonosuyas (de Vizcaíno Casas, 1984) burlaba la disgregación de las autonomías y parecía exagerada, marcada por la ideología derechista del guionista. Hoy día no hace falta ser de derechas para ver que se quedó muy corta comparada con la realidad actual, que en numerosas ocasiones llega a extremos esperpénticos.

España tiende a la disgregación. Cada una de sus diecisiete autonomías tiene su gobierno e instituciones, de forma que es un país que acaba manteniendo algo similar a diversos Estados. Éstos solicitan mayores prebendas cada vez en más campos (a parte de que algunas facciones procedentes de Cataluña y del País Vasco solicitan independencia). Este fenómeno se ve reflejado, en el campo académico, en la multiplicación de las universidades y de las Agencias de Evaluación de la Calidad y Acreditación.

A continuación ofreceré un ejemplo de los numerosos casos que, según entiendo, destacan por tener un nacionalismo notablemente politizado, como es el caso catalán, que considero que influye en la narración y la creación de su Historia.

Las autonomías hunden sus raíces en la Constitución de 1978, que recoge el derecho de autonomía de las regiones y nacionalidades que conforman la nación española. De ellas, hubo cuatro comunidades autónomas que accedieron a la autonomía "por vía especial”: Galicia, Andalucía, el País Vasco y Cataluña. Cataluña ha adquirido actualmente una preeminencia política que antaño no tenía, y que históricamente opino que está injustificada.

Así puede apreciarse por ejemplo en un lugar virtual tan conocido como la Wikipedia, que recoge lo que más consulta la sociedad en general (sean más o menos científicas o acertadas sus voces). La voz Comunidad autónoma afirma que el derecho de autonomía "daba respuesta a un problema que había surgido repetidamente en la Historia de España como resultado de las diferentes identidades sobre las que se ha construido la unidad de España" 5. 
El ejemplo ilustrativo recoge las palabras clave a las que la sociedad recurre cuando apela a la identidad de un lugar: apela a la Historia. De ello puede derivar un problema, cuando una parte ínfima de la sociedad sabe Historia, disciplina que la mayoría conoce en su versión de divulgación, que es la faceta que interesa en el presente ensayo. Históricamente, la actual Cataluña siempre había formado parte de la Corona de Aragón, como es conocido en la comunidad de historiadores. Para mí es difícil comprender por qué políticamente Cataluña adopta hoy día tanta preeminencia con respecto a Aragón. En cualquier caso, dada la estructura actual de las autonomías, y dada la poca información que ofrecen las fuentes más usadas por la sociedad (estilo Wikipedia), gran parte de la sociedad piensa que Cataluña tuvo una enorme importancia política en el pasado, sin imaginar si quiera que perteneció durante numerosos siglos a la Corona de Aragón, a la que se supeditaba.

También dice la misma Wikipedia de Cataluña que "su Historia y su lengua son, para muchos de sus habitantes, la base de su identidad colectiva" 6 . Como cualquier nacionalismo, es normal que apele a la diferencia idiomática, en el mismo sentido que podrían apelar numerosas regiones que hablan por ejemplo bable, gallego, vascuence o cualquier otra lengua de la rica pluralidad que conforma España. Aunque respeto a la riqueza idiomática, opino que acaso se haya exagerado la importancia de algunas lenguas debido a la politización de la Historia. En ese sentido, el catalán haya adoptado un protagonismo un tanto exagerado ${ }^{7}$.

\section{Conclusiones: sopesando lo positivo y lo negativo de la documentación en red}

La digitalización de documentación es necesaria y conlleva innumerables ventajas científicas y culturales de sobra conocidas. Algunas de ellas se han enumerado al inicio de este ensayo, como la preservación documental o la difusión de la información. La digitalización sería perfecta si se hiciese filantrópicamente con fines positivos, por ejemplo, para conservar el patrimonio documental o conocer mejor el pasado.

Sin embargo, la reflexión sobre los futuribles hace plantear que acaso no todo sean ventajas en la digitalización documental, si esa digitalización se usa con fines políticos. Para ilustrar la duda cabe plantear la pregunta inicial ¿qué sucedería si...? y cabe continuarla con: ¿si el día de mañana se presentasen estudios históricos realizados con aquellos documentos digitalizados por un Estado, con el fin de solicitar prebendas particularistas con fines políticos nacionalistas o independentistas? Sería un problema, porque eso iría en detrimento del Estado en conjunto, Estado que financió en parte o en su totalidad la digitalización de esos miles de documentos, en calidad de proyecto conjunto de un país.

Con el máximo respeto a la rica pluralidad de este país idiomática e ideológica, guardo la esperanza de que la digitalización y el acceso libre de la documentación sirva para aumentar el conocimiento científico de la Historia en favor tanto del enriquecimiento común como del entendimiento. Espero que no ayude a crear barreras artificiales procedentes de la politización de la Historia. 


\section{Notas:}

1. Página oficial: <http://www.rah.es/cdeb.htm>

2. Disponible en <http://www.youtube.com/watch?v=Ul7vq59-lTY> o en $<$ http:// www.youtube.com $/$ watch? $\mathrm{NR}=1 \& \mathrm{v}=\mathrm{c} 8 \mathrm{cJlf} 3 \mathrm{iO} 6 \mathrm{c}>$

3. Ley 52/2007 <http://www.boe.es/boe/dias/2007/12/27/pdfs/A53410-53416.pdf>

4. <http://pares.mcu.es/victimasGCFPortal/ staticContent.form;jsessionid=EC4FoF9113E894729F09A8AF60584481? view Name= $=$ presentacion $>$

5. <http://es.wikipedia.org/wiki/Autonom\%C3\%ADas>, consultado el 1 de enero, Cursivas de la autora

6. Wikipedia, Voz Cataluña, <http://es.wikipedia.org/wiki/Catalu\%C3\%B1a>

7. Por ejemplo, cuando en ciertas asignaturas universitarias de castellano se han impartido en catalán. También resulta sintomático que determinadas asignaturas de historia de carácter geográfico general se centren en cultura catalana exclusivamente, con la consiguiente carencia de perspectiva comparativa para el alumnado. Asimismo me resulta exagerado el incumplimiento del bilingüismo obligado entre el castellano y el catalán, como sucede en algunos congresos internacionales, con el consecuente problema de entendimiento.

\section{Referencias bibliográficas y fuentes electrónicas}

Beck, Humberto (2008) "Presentación: Sobre la Historia Contrafactual”, www.letraslibres.com [Consulta: 11 de diciembre de 2012].

Carabias Torres, Ana M. (2005): “Internet y la investigación Histórica: una versión moderna de la Biblioteca de Alejandría”, Iacobs Revista de Estudios Jacobeos y Medievales, (19-20), pp. 427-449.

Chartier, Roger (2012): ¿Muerte o transfiguración del lector?, Carlos V (sección: "Historiografía y recursos en la red. Recursos en Internet"), disponible en: <http://bib.cervantesvirtual.com/historia/ CarlosV/recurso 1.shtml>. [Consulta: 2 de febrero de 2012].

Constenla, T. (2011): "Franco, ese (no tan mal) hombre", El País, 30/05/2011, disponible en: <http:// www.elpais.com/articulo/cultura/Franco/mal/hombre/elpepicul/20110530elpepicul_2/Tes>. [Consulta: 11 de marzo de 2012].

Fabiani, Paolo (2009): The Philosophy of Imagination in Vico and Malebranche, Florencia, Firenze University Press, <http://www.fupress.com/Archivio/pdf/3622.pdf>, [Consulta: 11 de enero de 2012].

Fernández Izquierdo, Francisco (2006): "Investigar, escribir y enseñar Historia en la era de Internet. Presentación”, Hispania. Revista Española de Historia, LXVI, 222, pp. 11-30.

Fernández-Mayoralas Palomeque, Juan (2000): “Matemáticas de la Historia”, Memoria y Civilización, 3, pp. 275-309.

Febvre, Lucien (1970): Combates por la Historia, Barcelona, Ariel.

Lucas, Antonio (2011): "La Real Academia de la historia 'no corregirá' la polémica biografía de Franco", elmundo.es, 30/05/2011, disponible en: <http://www.elmundo.es/elmundo/2011/05/30/ cultura/1306744704.html>. [Consulta: 11 de marzo de 2012].

Pons (2006), Anaclet: “La Historia Maleable. A propósito de Internet”, Hispania. Revista Española de Historia, vol. LXVI, 222, pp. 109-130.

Portal de víctimas de la Guerra Civil y Represaliados del franquismo, <http://pares.mcu.es/ victimasGCFPortal/staticContent.form;jsessionid=EC4FoF9113E894729Fo9A8AF60584481? viewName $=$ presentacion $>$. [Consulta: 11 de marzo de 2012]. 
MEI, II, Vol. 3, nº 4, pág. 125

RAE (2010): Diccionario de la Real Academia de la Lengua, 22 ed., Madrid, disponible en: http:// www.rae.es/rae.html.

Towson, Nigel (2004): Historia virtual de España (1870-2004): ¿Qué hubiera pasado si...?, Madrid, Taurus.

Wikipedia, Voz Cataluña, <http://es.wikipedia.org/wiki/Catalu\%C3\%B1a>, [Consulta: 11 de diciembre de 2011].

Zozaya Montes, Leonor (2009): "El desarrollo de competencias en Historia y Ciencias y Técnicas Historiográficas a través de un espacio virtual en Internet”, Relada (Revista Electrónica de ADA), Vol. 3 (3), pp. 240-248, disponible en: <http://polired.upm.es/index.php/relada/article/view/83>. [Consulta: 11 de marzo de 2012]. 